\title{
Symptom Profile of Injured Motorists on the Structured Inventory of Malingered Symptomatology
}

\author{
Zack Z. Cernovsky
}

\section{ABSTRACT}

Background: Recent extensive content analyses demonstrated that the items of the Structured Inventory of Malingered Symptomatology (SIMS) have no capacity to differentiate malingerers from legitimate medical patients: all items list or assess legitimate medical symptoms. We examined which SIMS items are the most frequently endorsed by injured motorists.

Method: De-identified archival data of 23 survivors (mean age $=38.0$, SD=12.8) of high impact motor vehicle accidents (MVAs) contained their SIMS scores, their responses to the Brief Pain Inventory, Morin's Insomnia Severity Index, Rivermead Post-Concussion Symptoms Questionnaire, and to the Post-MVA Neurological Symptoms scale.

Results: All SIMS items which were endorsed by more than $43 \%$ of the patients in the directions scored by the SIMS as indicative of "malingering" were selected. Twenty-five items met this criterion. On a closer examination, all these 25 items are legitimate psychological and neuropsychological symptoms typically experienced by injured motorists, such as depression, impaired sleep, and postconcussive symptoms (memory and concentration problems, impaired balance) and whiplash symptoms (numbness in the limbs, instances of reduced muscular control over some of the limbs).

Discussion and Conclusions: The 25 endorsed items are consistent with the polytraumatic symptom profile of injured patients. In a travesty of psychological assessment, these symptoms are scored in the SIMS as denoting "malingering".

Keywords: malingering, SIMS, polytraumatic symptom pattern, car accidents.

Submitted : February 25, 2021

Published : March 20, 2021

ISSN: 2593-8339

DOI: $10.24018 /$ ejmed.2021.3.2.739

\section{Z. Z. Cernovsky*}

Dept. of Psychiatry, Western University, London, Ontario, Canada. (e-mail: drcernovsky@ gmail.com)

*Corresponding Author

\section{INTRODUCTION}

The Structured Inventory of Malingered Symptomatology (SIMS) [1] is a widely used test of malingering by psychologists contracted by car insurance companies. The test consists of items describing legitimate medical symptoms [2]-[5], but these are fallaciously scored as indicative of malingering by the SIMS scoring system.

The SIMS consists of 75 items. Each item counts one point if endorsed in the direction interpreted as malingering. The user obtains a total score: the patients scoring $>14$ points are classified as malingerers, see the SIMS manual [6].

Since it has been irrefutably shown that all SIMS items represent legitimate symptoms, persons who report more medical symptoms on the SIMS obtain higher SIMS scores, i.e., they are more likely to be classified as malingerers, whether or not their symptoms are genuine or feigned [7]. The test does not differentiate between malingerers and legitimate patients.

More than $50 \%$ of the SIMS items assess post-concussive and whiplash symptoms, as common in survivors of car accidents [8].

The present study evaluates which SIMS items are the most frequently endorsed by injured motorists.

\section{METHOD}

De-identified archival data were available for 23 survivors of high impact motor vehicle accidents (MVAs) in Canada: 8 males and 15 females, age 19 to 60 years (mean age $=38.0$, $\mathrm{SD}=12.8$ ), with education from 10 to 18 years (mean $=14.1$, $\mathrm{SD}=1.9)$. Their average scores were 17.2 $(\mathrm{SD}=11.0)$ on the Post-MVA Neurological Symptoms scale [9], 6.3 (SD=1.3) on the "average pain" item of the Brief Pain Inventory [10], and $23.7(\mathrm{SD}=3.0)$ on Morin's Insomnia Severity Index [11]. All patients in this sample could be classified as experiencing some degree of the post-concussion syndrome (scores ranging from 24 to 58 on the Rivermead scale [12], [13], with mean=37.4, $\mathrm{SD}=13.2$ ). The time elapsed since the patient's MVA ranged from 7 to 217 weeks, with the average at 81.5 weeks $(\mathrm{SD}=55.8)$. They all still experienced active postaccident symptoms that required therapy.

In all 23 cases, the car was damaged to the extent of being deemed by insurance assessors as not worthy of repair. Thus, the physical nature of their vehicular collision (high impact) makes the accusation of malingering less plausible. Such accidents are too rare without involving injuries of neuropsychological nature, especially symptoms in the postconcussion whiplash spectrum. 
Some psychologists may still erroneously assume that cerebral concussions occur seldom without visible head injuries and without a complete and prolonged loss of consciousness. The excellent neuropathological research by Bennet Omalu [14], [15] on players of American football demonstrated that cerebral damage in concussions occurs with sudden acceleration or deceleration of the head even in persons who neither sustained visible head injuries nor fully lost consciousness. These persons, within minutes after their concussion, may still be able to perform some simple physical tasks such as those involved in playing football. However, microvascular injuries and axonal shearing with subsequent neurotoxicity do occur in such incidents.

All 23 patients completed the SIMS [6]. Their average score was 26.5 (16.0), i.e., far above the cutoff of malingering stipulated in the SIMS manual as $>14$ points.

\section{RESULTS}

All SIMS items which were endorsed by at least $43 \%$ of our patients in the direction indicative of "malingering" were selected. Twenty-five items met this criterion. The Table 1 rank orders these 25 items according to frequency of their endorsement by our 23 injured motorists.

Not even one of these 25 items seems indicative of malingering. In fact, the content of these items and the direction of their endorsement are consistent with the typical polytraumatic symptom pattern of injured motorists that includes pain, disruption of sleep by pain (Item 32), fatigue related to persistent pain (Item 52), impaired memory and concentration as a part of the post-concussion syndrome (Items 18, 30, 25, 53), depression (Items 6, 23, 19, 2, 37, 47, 24), post-concussive symptoms such as impaired balance (Item 26) or low performance on some arithmetic tasks (Items 68,73 ) or on a logical reasoning task (Item 7), and typical whiplash symptoms such as instances of reduced muscular control over the limbs (Item 35) and numbness in the limbs (Item 59).

Some readers might wonder why about $3 / 4$ of our sample endorsed the Item 10 "I have noticed that my body changes shape even though my weight stays the same"). A feasible explanation is as follows. Injured motorists usually experience pain in lumbosacral or cervical spine which might radiate into the limbs [16]. Persistent chronic pain leads to a change towards a more sedentary lifestyle with a considerable reduction in exercise or physical activity: there is, over time, a corresponding change in overall body composition, i.e., a reduction in muscle mass and an increase in body fat. This can indeed result, over time, in a subtle change in body shape, all while the overall weight remains unchanged, as described in Item 10. The patients in our sample were assessed on the average 81.5 weeks $(\mathrm{SD}=55.8)$, i.e., about a year and a half after their MVA: for most of these patients, the accident eventually resulted in a major decrease in levels of daily physical activity.

The Item 60 ("I can't seem to express my feelings") seems to refer to alexithymia which has been statistically shown to occur frequently with depressive symptoms, as a part of the syndrome, in a Finnish study on 2,018 persons [17]. Depression is common in injured motorists.
TABLE 1: MOST FREQUENTLY ENDORSED SIMS ITEMS

\begin{tabular}{|c|c|}
\hline $\begin{array}{l}\text { SIMS items endorsed by at least } 43 \% \text { of patients in } \\
\text { the direction scored by the SIMS as indicative of } \\
\text { malingering: }\end{array}$ & $\begin{array}{l}\% \text { of patients } \\
\text { endorsing the } \\
\text { item }\end{array}$ \\
\hline 32. I have trouble sleeping. & $78.3 \%$ \\
\hline 52. I do not seem to have the energy I used to have. & $78.3 \%$ \\
\hline $\begin{array}{l}\text { 10. I have noticed that my body changes shape even } \\
\text { though my weight stays the same. }\end{array}$ & $73.9 \%$ \\
\hline $\begin{array}{l}\text { 18. More than three times a day I find myself getting } \\
\text { up to get something only to forget what it was. }\end{array}$ & $69.6 \%$ \\
\hline 6. I seldom laugh. & $60.9 \%$ \\
\hline 23. I seldom cry. (inverse scoring) & $60.9 \%$ \\
\hline $\begin{array}{l}\text { 19. At times I am so depressed I welcome going to } \\
\text { bed early to "sleep it off." }\end{array}$ & $60.9 \%$ \\
\hline $\begin{array}{l}\text { 2. When my depression becomes too severe, I go out } \\
\text { for long walks or do some form of exercise to reduce } \\
\text { the tension. }\end{array}$ & $60.9 \%$ \\
\hline 37. As the day progresses my mood gets worse. & $56.5 \%$ \\
\hline $\begin{array}{l}\text { 26. Walking is difficult for me because of my } \\
\text { problems with balance. }\end{array}$ & $52.2 \%$ \\
\hline $\begin{array}{l}\text { 35. Sometimes my muscles go limp for no apparent } \\
\text { reason so that my arms and legs feel as if they weigh } \\
\text { a ton. }\end{array}$ & $47.8 \%$ \\
\hline $\begin{array}{l}\text { 53. When I can't remember something, hints do not } \\
\text { help. }\end{array}$ & $47.8 \%$ \\
\hline 68. (Arithmetic task of moderate difficulty) & $47.8 \%$ \\
\hline 60. I can't seem to express my feelings. & $47.8 \%$ \\
\hline 17. My mood is worse at night. & $47.8 \%$ \\
\hline 47. I am depressed all the time. & $43.5 \%$ \\
\hline 30. I have difficulty remembering today's date. & $43.5 \%$ \\
\hline 14. (Question about geography of the United States) & $43.5 \%$ \\
\hline 63. (Question about history of the United States) & $43.5 \%$ \\
\hline $\begin{array}{l}\text { 24. The more depressed I get, the more I want to eat. } \\
\text { 59. Although I am able to move them with no }\end{array}$ & $43.5 \%$ \\
\hline $\begin{array}{l}\text { difficulty, I have noticed several parts of my limbs } \\
\text { are numb. }\end{array}$ & $43.5 \%$ \\
\hline $\begin{array}{l}25 . \text { At times I've been unable to remember the names } \\
\text { or faces of close relatives so that they seem like } \\
\text { complete strangers. }\end{array}$ & $43.5 \%$ \\
\hline $\begin{array}{l}\text { 71. Once a week I suddenly find myself cold even } \\
\text { though the actual temperature is warm. }\end{array}$ & $43.5 \%$ \\
\hline 73. (Arithmetic task of moderate difficulty) & $43.5 \%$ \\
\hline 7. (Logical reasoning task) & $43.5 \%$ \\
\hline
\end{tabular}

The Item 25 ("At times I've been unable to remember the names or faces of close relatives so that they seem like complete strangers") may also deserve some comments. Recalling mentally the face of certain relatives in their absence is less easy for patients tired by persistent pain and by pain related insomnia, even though they would recognize them in photographs or when present physically without any difficulty. Persons with artistic skills in human drawing may confirm that painting a face of a close relative from memory when not tired or distracted by pain is easier when not exhausted by pain, insomnia, and the post-concussion syndrome. For the same reasons, the post-concussive patient could complain that the name of a person with whom there was no contact for several years is "at the tip of the tongue," but not available for an immediate retrieval as prior to the accident.

Bouts of hypothermia (Item 71) can be experienced by patients with certain medical conditions, for example, spinal cord injury [18], mild hypothyroidism, or as a side-effect of some psychiatric medications [19]. In rare cases, a spontaneous periodic hypothermia [20] occurs recurrently and is centrally mediated without an identifiable systemic cause or brain lesion.

The Item 17 ("My mood is worse at night") could, in some cases, describe heightened levels of depression or anxiety during the patient's attempts to fall asleep. When external stimulation is reduced to a minimum at night while the 
injured patient attempts to sleep, internal stimuli such as pain, intrusive anxious or depressive thoughts, and paresthesias in the limbs (e.g., an annoying tingling or numbness), have more central place in the focus of attention. The patient might feel more overwhelmed by the aversive internal stimuli than during the day when the attention is often helpfully distracted by the surrounding events.

The Item 14 examines whether the patient knows how many states there are in the USA. Some US residents might find it surprising that $43.5 \%$ of our 23 Canadian patients failed to know the correct response. Probably, many US citizens would similarly fail to recall how many provinces and territories there are in Canada.

The Canadian patients also experienced difficulties with Item 63 (question about a past US president).

The full text of items $7,14,63,68$, and 73 is reproduced elsewhere, as a part of SIMS Low Intelligence (LI) scale [4]. Even a brief perusal of the LI items shows that they have no potential to differentiate between persons with genuinely low intelligence and those feigning the intellectual deficit.

\section{DISCUSSION}

The items in the Table 1 summarize the (false) reasons for which the injured patient is classified as a malingerer. The 25 items represent certain aspects of the typical polytraumatic symptom profile of injured motorists [21]. None of the 25 items has any capacity to determine if the symptom is genuine or feigned.

If an injured patient endorses all 25 items listed in Table 1, what interpretation is recommended by the SIMS manual for psychological reports on that patient? An example provided by the SIMS, page 15 , for total scores > 14 points, is as follows: "This individual endorsed a high frequency of symptoms that are highly atypical in patients with genuine psychiatric or cognitive disorders, raising the suspicion of malingering."

Since all 75 SIMS items represent legitimate medical symptoms [2]-[5], it appears that only healthy persons (those not reporting any medical symptoms) are safe from being iatrogenically misclassified by SIMS psychologists as "suspected malingerers." Thus, injured motorists that are applying for insurance owed benefits such as payment for therapies are at a high risk of having their claim considered as "suspect" by insurance clerks who were advised so by a SIMS psychologist, with the result of interminable delays or flat rejections of lawful claims.

\section{CONCLUSION}

The most frequently endorsed SIMS items by injured motorists are those consistent with the typical polytraumatic symptom pattern of patients after car accidents: none of these SIMS items has any reasonable capacity to determine whether the particular post-accident symptom is genuine or feigned.

The SIMS is an inherently false test that should never be used in assessments of real persons.

\section{ACKNOWLEDGMENT}

The author thanks to Abe Cernovsky, BA, for his editorial assistance in this research project.

\section{REFERENCES}

[1] Smith GP, Burger GK. Detection of malingering: Validation of the Structured Inventory of Malingered Symptomatology (SIMS). Journal of the American Academy on Psychiatry and Law. 1997; 25:180-183.

[2] Cernovsky ZZ, Mendonça JD, Ferrari JR, Sidhu G, Velamoor V, Mann SC, et al. Content Validity of the Affective Disorder Subscale of the SIMS. Archives of Psychiatry and Behavioral Sciences. 2019; 2(2):33 39.

[3] Cernovsky Z, Bureau Y, Mendonça J, Velamoor V, Mann S, et al Validity of the SIMS Scales of Neurologic Impairment and Amnestic Disorder. International Journal of Psychiatry Sciences. 2019;1(1):1319.

[4] Cernovsky ZZ, Mendonça JD, Ferrari JR, Bureau YRJ. Content validity of SIMS low intelligence scale. International Journal of Research in Medical Science. 2019; 1(1):21-25.

[5] Cernovsky Z, Mendonça JD, Oyewumi LK, Ferrari JR, Sidhu G, Campbell R, et al. Content Validity of the Psychosis Subscale of the Structured Inventory of Malingered Symptomatology (SIMS). International Journal of Psychology and Cognitive Science. 2019;5(3):121-127.

[6] Widows MR, Smith GP. Structured Inventory of Malingered Symptomatology - Professional Manual. Lutz, FL: PAR Inc., 2005.

[7] Cernovsky ZZ, Mendonça JD, Ferrari JR. Meta-Analysis of SIMS Scores of Survivors of Car Accidents and of Instructed Malingerers. Archives of Psychiatry and Behavioral Sciences. 2020;3(1):1-11.

[8] Cernovsky ZZ, Ferrari JJR, Mendonça JD. Pseudodiagnoses of Malingering of Neuropsychological Symptoms in Survivors of Car Accidents by the Structured Inventory of Malingered Symptomatology. Archives of Psychiatry and Behavioral Sciences. 2019; 2(1): 55-65.

[9] Cernovsky ZZ, Istasy PVF, Hernández-Aguilar ME, Mateos-Moreno A, Bureau Y, Chiu S. Quantifying Post Accident Neurological Symptoms Other than Concussion. Archives of Psychiatry and Behavioral Sciences. 2019, Volume 2, Issue 1, 5054.

[10] Cleeland CS. The Brief Pain Inventory - User Guide. Houston, TX: The University of Texas - M. D. Anderson Cancer Center, 2009.

[11] Morin CM, Belleville G, Bélanger L, and Ivers H. The insomnia severity index: psychometric indicators to detect insomnia cases and evaluate treatment response. Sleep. 2011; 34:601-608.

[12] King NS, Crawford S, Wenden FJ, Moss NEG, Wade DT. The Rivermead Post Concussion Symptoms Questionnaire: a measure of symptoms commonly experienced after head injury and its reliability. Journal of Neurology. 1995;242:587-592.

[13] Cernovsky ZZ, Mann SC, Velamoor V, Oyewumi LK, Diamond DM, Litman LC. Validation of the Rivermead Post-Concussion Symptoms Questionnaire (RPQ) on Patients Injured in High Impact Car Accidents. Archives of Psychiatry and Behavioral Sciences. 2021;4(1):14-22. doi.org/10.22259/2638-5201.0401003

[14] Omalu BI, DeKosky ST, Minster RL, Kamboh MI, Hamilton RL, \& Wecht CH. Chronic traumatic encephalopathy in a National Football League player. Neurosurgery. 2005;57: 128-34.

[15] Omalu BI, DeKosky ST, Hamilton RL, Minster RL, Kamboh MI, Shakir AM, \& Wecht $\mathrm{CH}$. Chronic traumatic encephalopathy in a National Football League player: Part II. Neurosurgery. 2006;59:108692.

[16] Cernovsky ZZ, Mann SC, Velamoor VR, and Oyewumi LK. The Need for Three Separate Parallel WAD Ratings of Whiplash Injuries to Cervical, Lumbosacral, and Thoracic Spine in Clinical Assessments of Injured Motorists. European Journal of Medical and Health Sciences. 2021;3(1):1-6. doi: 10.24018/ejmed.2021.3.1.699.

[17] Honkalampia K, Hintikkaa J, Tanskanena A, Lehtonena J, Viinamäkia $\mathrm{H}$. Depression is strongly associated with alexithymia in the general population. Journal of Psychosomatic Research. 2000;48(1): 99-104. doi.org/10.1016/S0022-3999(99)00083-5.

[18] Khan S, Plummer M, Martinez-Arizala A, and Banovac K. Hypothermia in Patients With Chronic Spinal Cord Injury. The Journal of Spinal Cord Medicine. 2007,30(1);27-30.

[19] Zonnenberg C, Bueno-de-Mesquita JM, Ramlal D, and Blom JD Hypothermia due to Antipsychotic Medication: A Systematic Review. Frontiers in Psychiatry. 2017 (September 7) doi.org/10.3389/fpsyt.2017.00165

[20] Kloos RT. Spontaneous periodic hypothermia. Medicine (Baltimore). 1995 Sep;74(5):268-80. doi: 10.1097/00005792-199509000-00004. 
European Journal of Medical and Health Sciences www.ejmed.org

[21] Gutierrez J, Nosonova V, Cernovsky Z, Fattahi M, Tenenbaum S. Gutierrez Questionnaire for Assessments of Patients after Car Accidents. Archives of Psychiatry and Behavioral Sciences. 2019;2(2):10-21.

Zack Z. Cernovsky was born in 1947 and holds the Ph.D. in clinical psychology from the University of Zürich, Switzerland, 1986. He is the professor of psychiatry in the medical school of Western University, Canada. Professor Cernovsky has published close to 200 scientific articles in the field of psychiatry and medical psychology, and also chapters in university textbooks. 